\begin{tabular}{|l|l|}
\hline Postprint Version & 1.0 \\
\hline Journal website & $\underline{\text { http://www.springerlink.com/content/2q77ht0371h640p2/ }}$ \\
\hline Pubmed link & $\underline{\text { http://www.ncbi.nlm.nih.gov/pubmed/21698375 }}$ \\
\hline DOI & $10.1007 / \mathrm{s} 00228-011-1082-8$ \\
\hline
\end{tabular}

This is a NIVEL certified Post Print, more info at http://www.nivel.eu

\title{
Practice variation in a longitudinal perspective: a multilevel analysis of the prescription of simvastatin in general practices between 2003 and 2009
}

\author{
HENRIK OHLSSON ${ }^{1,3}$, MARCIA VERVLOET ${ }^{2}$ AND LISET VAN DIJK ${ }^{2}$
}

(1) Center for Primary Health Care Research, Lund University \& Region Skåne, CRC, ing 72, SUS, 20502 Malmö, Sweden

(2) NIVEL, Netherlands Institute for Health Services Research, P.O. Box 156, 3500 BN Utrecht, The Netherlands

(3) Unit of Social Epidemiology, Dept Clinical Science, Malmö, Lund University, CRC, ing 72, SUS, 205 02 Malmö, Sweden

\begin{abstract}
Purpose: The Dutch national guideline for Cardiovascular Risk Management advised in 2006 initiation of statin therapy in new patients with simvastatin. After the introduction of this guideline several measures were taken to increase the prescription of simvastatin in general practice. The aim of this paper is to describe the trend and interpractice variation in the relative share of simvastatin in statin prescription over a 7-year period (2003-2009) in Dutch general practices.

Methods: Data were used from the National Registration Network of General Practice (LINH) in the Netherlands. We used multilevel logistic regression analysis with individuals nested within practices. We evaluated the variance at different time points by the intra-class correlation (ICC).

Results: The share of simvastatin prescriptions of all statin prescriptions increased from $40 \%$ in 2003 to $82 \%$ in 2009 . While the ICC was above $20 \%$ during the periods 2005 to 2007 , it decreased rapidly from $25 \%$ in 2007 to only $9 \%$ in 2009 .

Conclusion: Our results indicate that a combination of several intervention measures seems to have been successful. While it seems like the implementation of the guidelines alone had some effect, there was an additional effect when reimbursement measures were implemented. Furthermore, the practice seemed to have affected the adoption of the national CVRM guideline as the variation initially increased after the guideline implementation. By including information on both the proportion of simvastatin prescribed and interpractice variation, we achieved a more complete evaluation of how simvastatin prescription developed over time and how it was related to the different measures taken.
\end{abstract}

\section{INTRODUCTION}

Statin use has considerably increased over the last few decades \{Walley, $2005 \# 2\}\left[^{1},{ }^{2}\right]$. Statins $(3$ hydroxy -3 - methyl glutaryl coenzyme A reductase inhibitors) are effective in lowering lipid levels and decrease the incidence of major coronary events, major cerebrovascular events, and revascularization $\left[{ }^{3},{ }^{4}\right]$. While their efficacy seems similar $\left[^{5}\right]$ prices of statins vary considerably. Patents for simvastatin and 
pravastatin have expired and this is accompanied by lower prices. To reduce costs, the prescription of cheaper statins has been promoted in several countries, primarily by reimbursement measures.

In Norway simvastatin is the first-line lipid-lowering therapy $\left[{ }^{6}\right]$ and since 2005 it has also been the only statin reimbursed for new users. Those patients who were prescribed a different statin when the measure became effective had to switch within a 1 -year transition period $\left[{ }^{7}\right]$. Other statins are only reimbursed in cases in which there are solid medical reasons. The share of simvastatin rapidly increased later. While in May $2005,48 \%$ of all new users were prescribed simvastatin, this figure increased to $62 \%$ a month after the measure had become effective (1 June 2005) and to $92 \%$ in $2006\left[^{7}\right]$. In 2006, Finland introduced a restricted reimbursement policy on statins similar to the Norwegian measure. As in Norway, there was an increase in the prescription of simvastatin $\left[{ }^{8}\right]$. Also, measures in other countries (such as Austria, Sweden, and Denmark) where expensive statins are not or only partly reimbursed show increasing trends toward the prescription of cheaper statins $\left[{ }^{8}\right]$.

Another way to stimulate the prescription of preferred statins is to include them in guideline recommendations, as was done for example in Skane, Sweden, in March 2003. There, the share of simvastatin slightly increased (from $15 \%$ to $22 \%$ ) during the 9 months after the guideline was published $\left[^{9}\right]$. In the Netherlands, the national guideline for Cardiovascular Risk Management (CVRM guideline) also recommends initiation of statin therapy with simvastatin or pravastatin, regardless of age and (co)morbidity of the patient $\left[{ }^{10}\right]$.

After its introduction in November 2006, two major measures were taken to increase the prescription of simvastatin. First, a large-scale nationwide program to stimulate the implementation of the prescription advices in the CVRM guideline was carried out in primary care by the Institute for Rational Use of Medicine (IVM) and the Netherlands College of General Practitioners (NHG) from 2008 to 2010 (Fig. 1). The primary aim of this program was to increase the share of simvastatin among new users (up to $>80 \%$ ). A major part of this program included specific training in Pharmacotherapy Audit Meeting groups (PTAMs). Although voluntary, almost all GPs and pharmacists participate in a local PTAM. PTAMs are a regular series of meetings where GPs and public pharmacists exchange information and opinions on pharmaceutical therapy in order to improve the rationality of pharmaceutical care $\left[{ }^{11}\right]$. Within the frame of the CVRM implementation program, PTAMs were stimulated to make agreements on simvastatin prescription to new users. Other elements of the implementation program included an individual training program for general practitioners and an electronic support system integrated into the general practitioners' computer system. In total, two thirds of all general practitioners participated in at least one program activity $\left[{ }^{12}\right]$.

The second development was the fact that, as of January 2009, reimbursement for statins is limited for both new and existing users. Only prescriptions for simvastatin and pravastatin are always reimbursed and not checked, while health insurance companies only reimburse other statins if the prescriber provides a written declaration that this is necessary for medical reasons, i.e., because simvastatin or pravastatin is not efficient $\left[{ }^{12}\right]$. For new users this means that prescribers should not start with statins other than simvastatin or pravastatin, since it has to be proven that simvastatin or pravastatin is not effective before others can be tried.

Against this background we aimed to monitor and evaluate the different measures taken to increase the relative share of simvastatin in new users of statins. In the Netherlands, the general practitioner holds a gatekeeper position and the majority of prescriptions (75-80\%) are prescribed by GPs; hence, we focused our study on general practices. As the CVRM guideline, the accompanying implementation program, and the reimbursement measure were introduced at different moments in time, our first specific aim was to estimate the trend in simvastatin prescription to new users. Since the first measure (CVRM guideline) became effective in 2006, we were investigating simvastatin prescription over a 7-year period (2003-2009) in order to see whether the trend had changed. Based on previous studies $\left[{ }^{9},{ }^{13},{ }^{14}\right]$ our hypothesis was that, first, the introduction of guidelines in 2006 would increase the share of simvastatin, and second, as previous studies have shown, this reimbursement measure is often the most efficient at increasing adherence to guidelines $\left[{ }^{9},{ }^{13},{ }^{14}\right]$, and this increase would be more prominent in 2009. Besides stimulating the overall level of simvastatin prescription the measures taken were also aimed at reducing unwanted variation across practices $\left[{ }^{13}\right]$. Therefore, we also investigated the variation among practices during the same 7 -year period. Based on previous studies our hypothesis was that the guideline implementation would at first increase practice variation and then, after an introductory phase, decrease it. As previous studies have suggested, 
simple analysis of differences between practices in their outcome means is insufficient $\left[{ }^{15}\right]$. One must also relate the variation (in the studied outcome) between practices to the variation within practices. The higher the share of the total variation in the outcome studied that can be attributed to the practices (interpractice variation), the more important the practices are for understanding the variation. For example, if practitioners at the same practice tend to act alike, then a large part of the variation will be attributed to the practice level and the practices will be of importance in understanding adherence to guidelines. This similarity can be assessed by using measures of variance and clustering, such as intraclass correlation (ICC) in a multilevel context. Therefore, our second specific aim was to investigate the interpractice variation in simvastatin prescription by using multilevel modeling.

\section{[FIGURE 1]}

\section{MATERIAL AND METHODS}

We used data from the Netherlands Information Network of General Practice (LINH) from the period 2003 up until 2009. Data were retrieved from electronic medical records kept by GP practices. The data include information on consultations, morbidity, prescriptions, and referrals. Practices and patients are representative of the Dutch population $\left[{ }^{16}\right]$. We selected all patients who had one or more prescription record with ATC code (Anatomical Therapeutic Chemical Classification system) C10AA from the years 2003 up to and including 2009. We analyzed the first statin prescription per patient included in the database. In order to diminish the risk of confounding, we excluded patients who received a drug from the ATC group C10AA during the 12 months preceding our study period. We also excluded patients who enlisted in their practice within a 12-month period prior to their first statin prescription, as well as practices with less than 10 patients with statin prescriptions during 1 year. Moreover, we excluded patients from the first year the practice was included in the database. In total we investigated 27,168 patients. Table 1 shows the number of patients and the number of practices included in the study at different time points.

\section{[TABLE 1]}

\section{Outcome variable}

The outcome variable was whether the first individual statin prescription was a simvastatin prescription (ATC code: C10AA01) or not.

\section{Statistical and epidemiological analysis}

Treatment with simvastatin among patients with lipid-lowering therapy patients were investigated by multilevel logistic regression analysis with individuals nested within practices. Practices were included in the analysis as random terms that allowed us to estimate the variance at the practice level. We developed one model for each of the 14 six-month periods included in the database: months 1-6 in 2003 (2003:1), months 7-12 in 2003 (2003:2), etc., up to months 7-12 in 2009 (2009:2). These models only included the random practice parameters in order to partition the variance into the different levels of analysis.

To facilitate the investigation of our research questions we evaluated the variance in the multilevel models $\left[{ }^{17}\right]$. The degree of similarity of outcomes at different levels can be expressed by the intra class correlation (ICC). The higher the ICC, the more important practices become for understanding variation in simvastatin prescription. We calculated the ICC using the latent variable method. We also calculated the $95 \%$ prevalence range for the practices by using the intercept plus/minus 1.96 times the square root of the between-practice variation and transformed back from the logit scale.

All analyses were performed using MLwiN software $\left[{ }^{18}\right]$. We estimated the model using MCMC methods and we present, for the fixed effects, odds ratios and a $95 \%$ confidence interval $(95 \% \mathrm{CI})$, and for the random effect, the median value of the 10,000 iterations together with a $95 \%$ CI.

\section{RESULTS}

As shown in Table 1, the share of all statin prescriptions that were for simvastatin increased from $40 \%$ in 2003:1 to $82 \%$ in 2009:2. In Table 2 it is illustrated that $39 \%$ of the patients at the median practice in 2003:1 received simvastatin. The figures at the practices at the 25 th and 75 th percentiles were $24 \%$ and 
$57 \%$ respectively. While the share at the median practice increased over time, the range between the 25 th and the 75th percentiles decreased from 33 in 2003:1 to 16 in 2009:2, indicating that general practices became more alike over time.

\section{[TABLE 2]}

In Table 3 the random effects from the multilevel logistic models are shown. The ICC was above $15 \%$ for all the periods studied except for the two final study periods. While the ICC was above $20 \%$ during the periods 2005:1 to 2007:2, it decreased rapidly from $25 \%$ in 2007:2 to only $9 \%$ in 2009:2. To sum up, the introduction of different initiatives taken to increase the prescription of simvastatin, seemed to increase the variation among practices, but after an introductory phase there was a clear decrease in practice variation. This was also accompanied by an increase in the prevalence of simvastatin from $69 \%$ in $2007: 2$ to $84 \%$ in 2009:2. Even though the 95\% CI around the variance estimate was rather broad for all the outcomes studied, it decreased toward the end of our study period. Furthermore, the $95 \%$ prevalence range for all periods studied was broad; for example, in $2006: 1$ it ranged from $11 \%$ to $95 \%$.

\section{[TABLE 3]}

In Fig. 2 the prevalence and a 95\% CI for all practices and all periods are shown. During the years 2003 to 2005 the median share of simvastatin was around $40-50 \%$. Moreover, all practices seemed to be relatively gathered around the mean; only a few practices had a high prevalence (60-70\%), while there also were a few practices with a rather low prevalence (10\%). In 2006 there was a large increase in the median prevalence of simvastatin (from $60 \%$ in $2006: 1$ to $72 \%$ in $2006: 2$ ). Figure $2 \mathrm{~g}$ and h shows that a large part of the practices increased their share of simvastatin, but a few practices in 2006:2 still lagged behind in their prescription of simvastatin. From 2007 to 2009 fewer and fewer practices had a low share of simvastatin prescriptions, which was accompanied by a decrease in the ICC.

\section{[FIGURE 2]}

\section{DISCUSSION}

Simvastatin prescriptions to new statin users in the Netherlands increased considerably between 2003 and 2009. While in 2003 only $40 \%$ of new statin users were prescribed simvastatin, in 2009 this rose to above $80 \%$. The increase started in the period 2006, the period during which several initiatives were taken to increase the prescription of simvastatin. In 2006, a national CVRM guideline was published recommending simvastatin as the first-choice treatment, a recommendation that also was the main subject of a large-scale implementation program in 2008-2010. In addition, as of January 2009 only simvastatin and pravastatin were reimbursed without restrictions, and during 2009 the adherence to guidelines increased even further. Data from a national pharmacy database showed that the trend stabilized during the first half of $2010\left[{ }^{12}\right]$.

An increase in the prevalence of guideline adherence does not necessarily imply better care since it could depend on a few practices with a very high prevalence, resulting in large differences between practices. However, the variation among practices clearly became smaller during our study period. The ICC decreased from $18 \%$ in 2003 to only $9 \%$ in 2009. The analysis of the variance also revealed that during 2006 and 2007 the ICC was higher compared with 2003 as well as 2009. This indicates variation between practices regarding adoption of the national CVRM guideline. However, after an introductory phase and when the reimbursement measure was implemented, an increasing number of practices adopted the guidelines and in 2009 the ICC was only 9\%. By including information on both mean and variance measures, we achieved a more complete evaluation on how the prescription of simvastatin developed over the last few years and how it related to the different measures taken.

Overall, our results suggest that the combination of intervention measures has been successful, with the reimbursement measure seemingly having the highest impact. This is in line with studies in other countries in the north of Europe where both reimbursement measures (Norway, Finland, Denmark, Austria) and the introduction of guidelines accompanied by a new budget structure (Sweden) also induced an increase in the prescription of simvastatin. $\left[{ }^{6}-{ }^{9},{ }^{14}\right]$ 
Practice variation is not necessarily inappropriate, but rather reflects equivalent traditions confronting a similar health problem. Furthermore, any measurement of any process will reveal some form of variation. However, every new statin user should use simvastatin and in fact any variation across practices in this situation is inappropriate and unwanted. An increasing number of studies have during the latter years investigated practice variation. The ICC at the practice level has varied between 5 and $40 \%$ depending of the outcome studied, indicating that in different areas large differences between practices exist for some outcomes and similar patients receive different care depending on the practice at which they are treated ${ }^{9}$, $\left.{ }^{13},{ }^{19}{ }^{22}\right]$. Our results show that this was also the case for new statin users, but that these differences have decreased considerably over time. This brings us to the fact that the present study contributes the literature on health care evaluation by investigating practice variation from a longitudinal perspective. This has rarely been done $\left[{ }^{23}\right]$. It allowed us to investigate how the practices where the physician worked actually affected the adoption of the national CVRM guideline. In 2006 and 2007 the ICC was at the highest level, indicating that practices differed in the uptake of the recommendations in the new guidelines. This information corresponds to previous knowledge, both regarding adoption of national or regional guidelines, $\left[{ }^{14}\right]$, but also regarding early adoption of newly marketed drugs $\left[{ }^{24}\right]$. Additionally, when the reimbursement measure was implemented the variation across practices actually decreased more rapidly. Typically, evaluations of health care quality are focused on the analyses of differences in the mean value of the outcome between different time periods or between different organisational units. However, if we realize what the ICC represents, we understand that partitioning of the variance allows us to investigate the importance of the practices to the prescription of simvastatin $\left[{ }^{15},{ }^{17}\right]$. Without focusing on the ICC, a comparison of the mean values can, for example, lead to the assumption that certain practices might be more or less effective. However, a low ICC reflects that simvastatin prescriptions are randomly distributed within the population of practices and that the practices do not provide additional information regarding simvastatin prescription.

Since our study is observational, several bias and confounding factors need to be considered. Given that there were several interventions during the study period it is difficult to disentangle the specific effects from one another, although the effect of the reimbursement measure seems to be strongest. As explained in previous studies it is often not enough to introduce guidelines alone in order to increase adherence and to reduce practice variation. It must be followed by other interventions as well (e.g., financial constraint, interventions in the physician's daily routine, information campaigns, etc.) $\left[{ }^{13},{ }^{22}\right]$. Moreover, it cannot be ruled out that other external influences besides the aforementioned interventions could provide an alternative explanation of our results. Nevertheless, it is reasonable to believe that the intense trend of increasing prescription of simvastatin occurring during our study period actually reflects the effect of the interventions. This is also strengthened by the fact that the results in our study are in line with previous studies investigating the implementation of guidelines for statin prescription. In the present investigation we did not include any individual or practice characteristics, as the recommendations state that every new user should use simvastatin and that all variation between practices is actually unnecessary. This aspect could be of interest for the future, as few previous studies have found any practice characteristics that actually explain the differences among practices or differences in the uptake of new guidelines. Moreover, as we did not have access to information at the physician level, parts of the variation at the practice level could actually be attributed to variation among physicians. While some previous studies have shown that the variation at the physician level accounted for about $50 \%$ of variation at the practice level $\left[{ }^{21}\right]$, others suggest that the variation at the physician level is more prominent. $\left[{ }^{25}\right]$

\section{CONCLUSION}

In conclusion, our results indicate that a combination of intervention measures taken to increase the relative share of simvastatin in new users of statins in general practices in the Netherlands seems to have been successful. There was an increase in simvastatin prescriptions to new statin users between 2003 and 2009 , from $40 \%$ to almost $85 \%$ and the practice variation, measured by the ICC, decreased from $18 \%$ to $9 \%$. While it seems like the implementation of the guidelines alone had some effect, there was an additional effect when reimbursement measures were implemented. Furthermore, we illustrated that the practice where the physicians worked seemed to have affected the adoption of the national CVRM guideline as the variation initially increased after guideline implementation. By including information on both mean and 
variance measures, we achieved a more complete evaluation of how the prescription of simvastatin has developed over the last few years and how it was related to the different measures taken.

\section{ACKNOWLEDGEMENTS}

We would like to thank the staff of LINH for their help in the data extraction and interpretation. This work was supported by the Dutch Ministry of Health.

\section{CONFLICT OF INTEREST}

None.

\section{REFERENCES}

1. Walley T, Folino-Gallo P, Stephens P, Van Ganse E (2005) Trends in prescribing and utilization of statins and other lipid lowering drugs across Europe 1997-2003. Br J Clin Pharmacol 60(5):543-551

2. Mann D, Reynolds K, Smith D, Muntner P (2008) Trends in statin use and low-density lipoprotein cholesterol levels among US adults: impact of the 2001 National Cholesterol Education Program guidelines. Ann Pharmacother 42(9):1208-1215

3. Law MR, Wald NJ, Rudnicka AR (2003) Quantifying effect of statins on low density lipoprotein cholesterol, ischaemic heart disease, and stroke: systematic review and meta-analysis. BMJ 326(7404):1423

4. Thavendiranathan P, Bagai A, Brookhart MA, Choudhry NK (2006) Primary prevention of cardiovascular diseases with statin therapy: a meta-analysis of randomized controlled trials. Arch Intern Med 166(21):2307-2313

5. Evaluation of the effects of statins (with particular consideration of atorvastatin). Cologne: Institut fur Qualität und Wirtschaftlichkeit im Gesundheitswesen; 2006

6. Devold HM, Molden E, Skurtveit S, Furu K (2009) Co-medication of statins and CYP3A4 inhibitors before and after introduction of new reimbursement policy. Br J Clin Pharmacol 67(2):234-241

7. Sakshaug S, Furu K, Karlstad O, Ronning M, Skurtveit S (2007) Switching statins in Norway after new reimbursement policy: a nationwide prescription study. Br J Clin Pharmacol 64(4):476-481

8. Martikainen JE, Saastamoinen LK, Korhonen MJ, Enlund H, Helin-Salmivaara A (2010) Impact of restricted reimbursement on the use of statins in Finland: a register-based study. Med Care 48(9):761-766 9. Ohlsson H, Lindblad U, Lithman T, Ericsson B, Gerdtham UG, Melander A et al (2005) Understanding adherence to official guidelines on statin prescribing in primary health care-a multi-level methodological approach. Eur J Clin Pharmacol 61(9):657-665

10. NHG/CBO. Cardiovasculair risicomanagement, Multidisciplinaire richtlijn. Utrecht; 2006 Van Dijk L, De Bakker D (2002) Professionalization of Dutch PRGs and volume and costs of frequently prescribed drugs. Zeitschr Gesundheitsw 4:292-304

Vervloet M, Brabers AEM, Pisters MF, van Dijk L (2010) Evaluatie van het Programma Doelmatigheid Cardiovasculair Risicomanagement (CVRM). Utrecht

13. De Jong JD, Groenewegen PP, Spreeuwenberg P, Schellevis F, Westert GP (2010) Do guidelines create uniformity in medical practice? Soc Sci Med 70(2):209-216

14. Ohlsson H, Merlo J (2007) Understanding the effects of a decentralized budget on physicians' compliance with guidelines for statin prescription; a multilevel methodological approach. BMC Health Serv Res 7:68

15. Merlo J, Ohlsson H, Lynch KF, Chaix B, Subramanian SV (2009) Individual and collective bodies: using measures of variance and association in contextual epidemiology. J Epidemiol Community Health 63(12):1043-1048

16. Verheij R, Van Dijk C, Abrahamse H, Davids R, Van den Hoogen H, Braspenning J et al (2010) Landelijk Informatienetwerk Huisartsenzorg. NIVEL/WOK, Feiten en cijfers over huisartsenzorg in Nederland. Utrecht/Nijmegen

17. Merlo J (2003) Multilevel analytical approaches in social epidemiology: measures of health variation compared with traditional measures of association. J Epidemiol Community Health 57(8):550-552

18. Rasbash J, Steele F, Browne W. A User's Guide to MLwiN, Version 2.0. Documentation Version 2.1e. London, UK: Centre for Multilevel Modelling, Institute of Education, University of London 2003 19. Mousques J, Renaud T, Scemama O (2010) Is the "practice style" hypothesis relevant for general practitioners? An analysis of antibiotics prescription for acute rhinopharyngitis. Soc Sci Med 70(8):11761184 
Ohlsson, H., Vervloet, M., Dijk, L. van. Practice variation in a longitudinal perspective - a multilevel-analysis of the prescription of simvastatin in general practices between 2003 and 2009. European Journal of Clinical Pharmacology: 2011, 67(12), 1205-1211

20. De Jong JD, Westert GP, Lagoe R, Groenewegen PP (2006) Variation in hospital length of stay: do physicians adapt their length of stay decisions to what is usual in the hospital where they work? Health Serv Res 41(2):374-394

21. Hjerpe P, Ohlsson H, Lindblad U, Bostrom KB, Merlo J (2011) Understanding adherence to therapeutic guidelines: a multilevel analysis of statin prescription in the Skaraborg Primary Care Database. Eur J Clin Pharmacol 67(4):415-423

22. De Jong JD, Groenewegen PP, Spreeuwenberg P, Westert GP, de Bakker DH (2009) Do decision support systems influence variation in prescription? BMC Health Serv Res 9:20

23. Groenewegen P, Westert G (2004) Is there a time trend in medical practice variations? A review of the literature and a critical analysis of theoretical approaches. J Public Health 12(3):229-236

24. Ohlsson H, Chaix B, Merlo J (2009) Therapeutic traditions, patient socio-economic characteristics and physicians' early new drug prescribing - a multilevel analysis of rosuvastatin prescription in South Sweden. Eur J Clin Pharmacol 65(2):141-150

25. Dalemo S, Hjerpe P, Ohlsson H, Eggertsen R, Merlo J, Bostrom KB (2010) Variation in plasma calcium analysis in primary care in Sweden-a multilevel analysis. BMC Fam Pract 11:43

\section{TABLES AND FIGURES}

Fig. 1 Timeline of relevant measurements for simvastatin prescription in the Netherlands

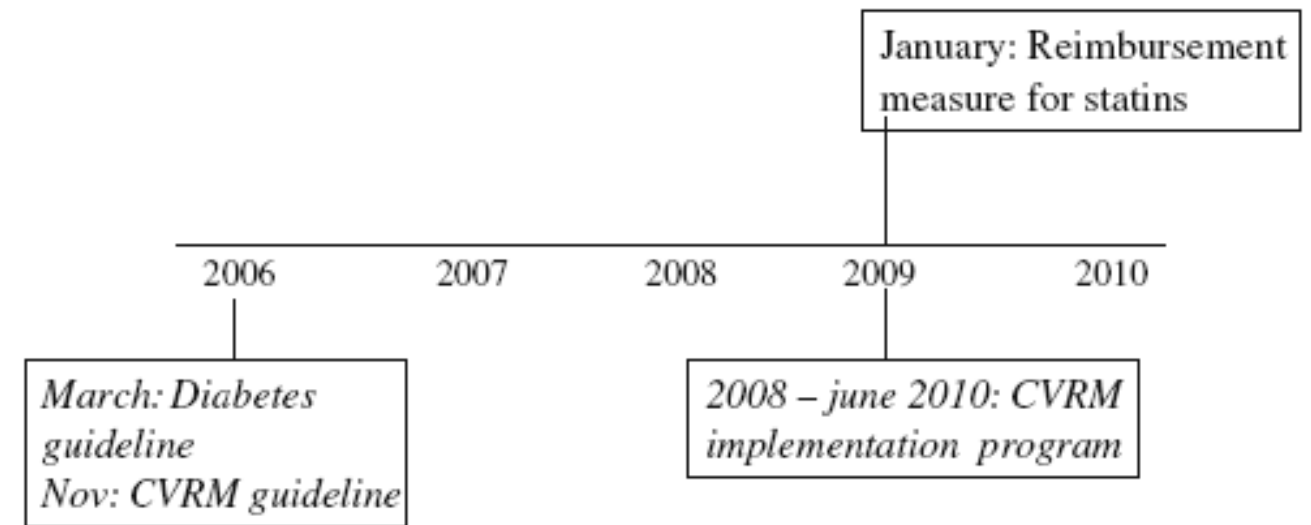


Table 1 Descriptive statistics of the 27,168 new users of statins in the Netherlands Information Network of General Practice (LINH) database during the years 2003 to 2009

\begin{tabular}{llll}
\hline Year & $\begin{array}{l}\text { Number of } \\
\text { patients }\end{array}$ & $\begin{array}{l}\text { Simvastatin } \\
(\%)^{\mathrm{a}}\end{array}$ & $\begin{array}{l}\text { Number } \\
\text { of practices }\end{array}$ \\
\hline $2003: 1$ & 1,357 & $537(40)$ & 68 \\
$2003: 2$ & 1,269 & $498(39)$ & 60 \\
$2004: 1$ & 1,176 & $493(42)$ & 54 \\
$2004: 2$ & 1,371 & $521(38)$ & 58 \\
$2005: 1$ & 2,061 & $953(46)$ & 66 \\
$2005: 2$ & 1,307 & $607(46)$ & 56 \\
$2006: 1$ & 2,593 & $1,622(63)$ & 63 \\
$2006: 2$ & 2,008 & $1,404(70)$ & 61 \\
$2007: 1$ & 2,975 & $1,939(65)$ & 101 \\
$2007: 2$ & 1,965 & $1,271(65)$ & 87 \\
$2008: 1$ & 2,296 & $1,410(61)$ & 97 \\
$2008: 2$ & 1,954 & $1,422(73)$ & 90 \\
$2009: 1$ & 2,855 & $2,241(78)$ & 106 \\
$2009: 2$ & 1,981 & $1,624(82)$ & 92 \\
\hline
\end{tabular}

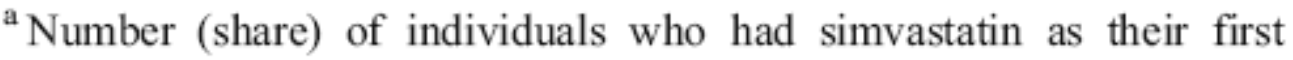
statin prescription 
Table 2 Share of all first-time statin prescriptions that were for simvastatin in the Netherlands Information Network of General Practice $(\mathrm{LINH})$ database during the years 2003 to 2009 . The values represent the share for the median practice $(25$ th and 75 th percentiles) for the specific time periods

${ }^{a}$ The value represents the median value for all practices. For example, regarding 2003:1, 39\% is interpreted as $39 \%$ of the patients at the median practice have received simvastatin. The figures at the practices at the 25 th and 75 th percentiles were $24 \%$ and $57 \%$ respectively

\begin{tabular}{ll}
\hline Year & Percentages \\
\hline $2003: 1^{\text {a }}$ & $39(24-56)$ \\
$2003: 2$ & $40(28-53)$ \\
$2004: 1$ & $43(31-52)$ \\
$2004: 2$ & $35(20-53)$ \\
$2005: 1$ & $43(28-67)$ \\
$2005: 2$ & $46(32-68)$ \\
$2006: 1$ & $67(38-80)$ \\
$2006: 2$ & $79(63-83)$ \\
$2007: 1$ & $70(57-83)$ \\
$2007: 2$ & $69(52-85)$ \\
$2008: 1$ & $62(47-79)$ \\
$2008: 2$ & $76(64-86)$ \\
$2009: 1$ & $85(73-90)$ \\
$2009: 2$ & $83(75-91)$ \\
\hline
\end{tabular}

Table 3 Results from the multilevel logistic regression analysis on adherence to statin prescription guidelines: 27,168 new users of statins from the Netherlands Information Network of General Practice (LINH) database during the years 2003 to 2009

\begin{tabular}{lccc}
\hline Year & Variance $(95 \% \mathrm{CI})$ & ICC, \% (95\% CI) & Mean prevalence and prevalence range (\%) \\
\hline $2003: 1$ & $0.74(0.44-1.24)$ & $18(12-27)$ & $38(10-77)$ \\
$2003: 2$ & $0.78(0.44-1.37)$ & $19(12-29)$ & $38(10-78)$ \\
$2004: 1$ & $0.66(0.39-1.18)$ & $17(10-26)$ & $41(12-77)$ \\
$2004: 2$ & $0.71(0.43-1.21)$ & $18(11-27)$ & $35(9-74)$ \\
$2005: 1$ & $1.12(0.73-1.78)$ & $25(18-35)$ & $45(9-87)$ \\
$2005: 2$ & $1.10(0.66-1.85)$ & $25(17-36)$ & $48(11-88)$ \\
$2006: 1$ & $1.62(1.07-2.56)$ & $33(25-44)$ & $60(11-95)$ \\
$2006: 2$ & $1.09(0.70-1.76)$ & $25(18-35)$ & $72(25-95)$ \\
$2007: 1$ & $1.00(0.69-1.47)$ & $23(17-31)$ & $70(24-94)$ \\
$2007: 2$ & $1.09(0.72-1.69)$ & $25(18-34)$ & $69(22-95)$ \\
$2008: 1$ & $0.80(0.54-1.18)$ & $19(14-26)$ & $64(24-91)$ \\
$2008: 2$ & $0.61(0.37-0.99)$ & $16(10-23)$ & $83(39-93)$ \\
$2009: 1$ & $0.47(0.29-0.74)$ & $13(8-18)$ & $84(63-94)$ \\
$2009: 2$ & $0.33(0.16-0.61)$ & $9(5-16)$ & \\
\hline
\end{tabular}


Ohlsson, H., Vervloet, M., Dijk, L. van. Practice variation in a longitudinal perspective - a multilevel-analysis of the prescription of simvastatin in general practices between 2003 and 2009. European Journal of Clinical Pharmacology: 2011, 67(12), 1205-1211

Fig. 2 Prevalence of simvastatin of all statins in new users and a $95 \% \mathrm{Cl}$ for all practices and for all study periods estimated from the multilevel logistic regression analysis. The $x$-axis shows the practices, while the $y$-axis represents the prevalence of simvastatin. a 2003:1, b 2003:2, c 2004:1, d 2004:2, e 2005:1, $f$ 2005:2, g 2006:1, h 2006:2, I 2007:1, j 2007:2, k 2008:1, I 2008:2, m 2009:1, n 2009:2
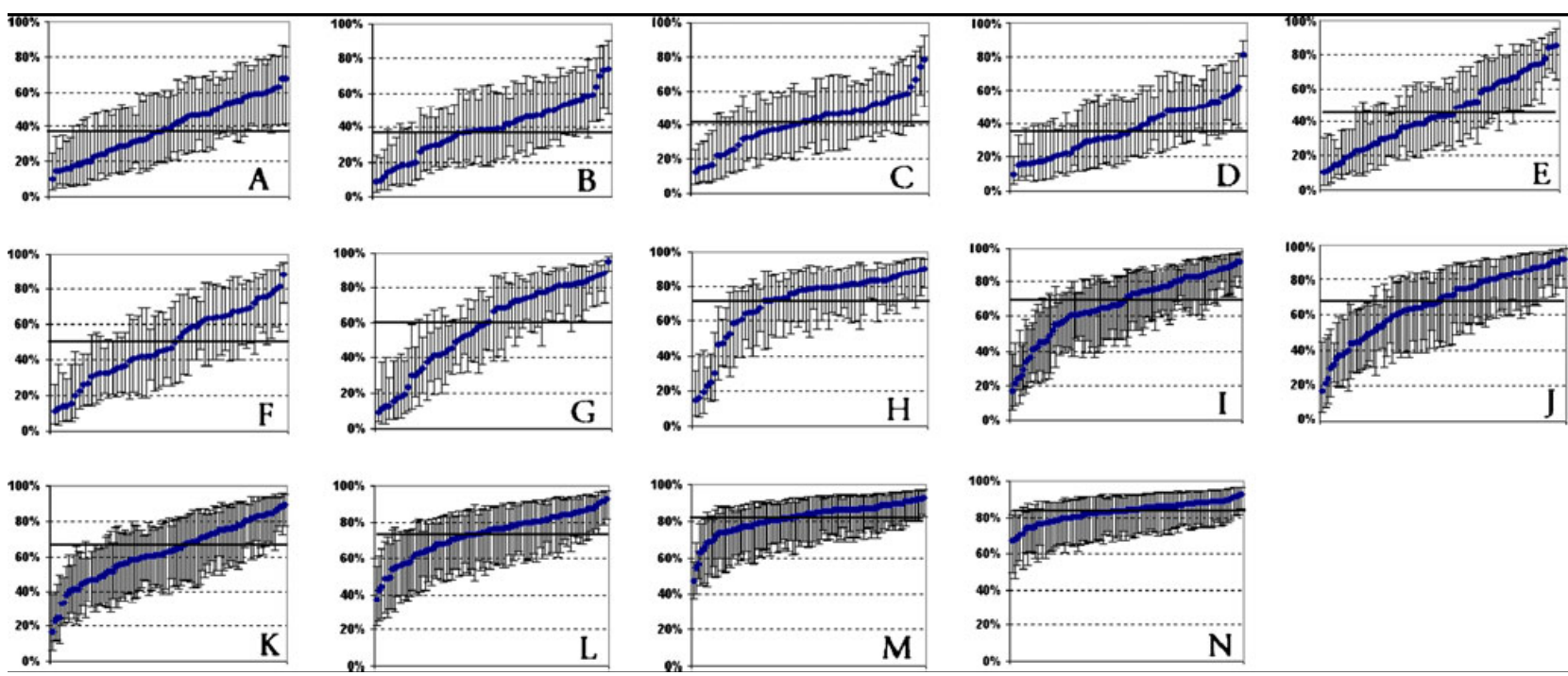